\title{
Ga-Se (Gallium-Selenium)
}

\section{H. Okamoto}

The Ga-Se phase diagram in [Massalski2] was redrawn from [1976Mof].

Figure 1 shows the Ga-Se phase diagram thermodynamically assessed by [2008Zhe] based on more experimental data than [1976Mof].

Ga-Se crystal structure data in Table 1 are as given in [Massalski2].

\section{References}

1976Mof: W.G. Moffatt, Ed., Handbook of Binary Phase Diagrams, Genium Publishing Co., Schenectady, NY, 1976 and supplements

2008Zhe: F. Zheng, J.Y. Shen, Y.Q. Liu, W.K. Kim, M.Y. Chu, M. Ider, X.H. Bao, and T.J. Anderson, Thermodynamic Optimization of the Ga-Se System, CALPHAD, 2008, 32(2), p 432-438

Table 1 Ga-Se crystal structure data

\begin{tabular}{|c|c|c|c|c|c|}
\hline Phase & Composition, at.\% Se & Pearson symbol & Space group & Strukturbericht designation & Prototype \\
\hline (Ga) & 0 & $o C 8$ & Cmca & $A 11$ & $\mathrm{Ga}$ \\
\hline \multirow[t]{3}{*}{ GaSe } & 50 & $h R 4$ & $R \overline{3} m$ & $\ldots$ & $\ldots$ \\
\hline & & $h P 8$ & $P \overline{6}$ & $\ldots$ & $\ldots$ \\
\hline & & $h P 16$ & $P 6_{3} m c$ & $\ldots$ & $\ldots$ \\
\hline$\beta \mathrm{Ga}_{2} \mathrm{Se}_{3}$ & $59.3-61$ & $c^{* *}$ & $\ldots$ & $\ldots$ & $\ldots$ \\
\hline$\alpha \mathrm{Ga}_{2} \mathrm{Se}_{3}$ & 60 & $m C 20$ & $C c$ & $\ldots$ & $\ldots$ \\
\hline$(\mathrm{Se})$ & 100 & $h P 3$ & $P 3_{1} 21$ & $A 8$ & $\gamma \mathrm{Se}$ \\
\hline
\end{tabular}

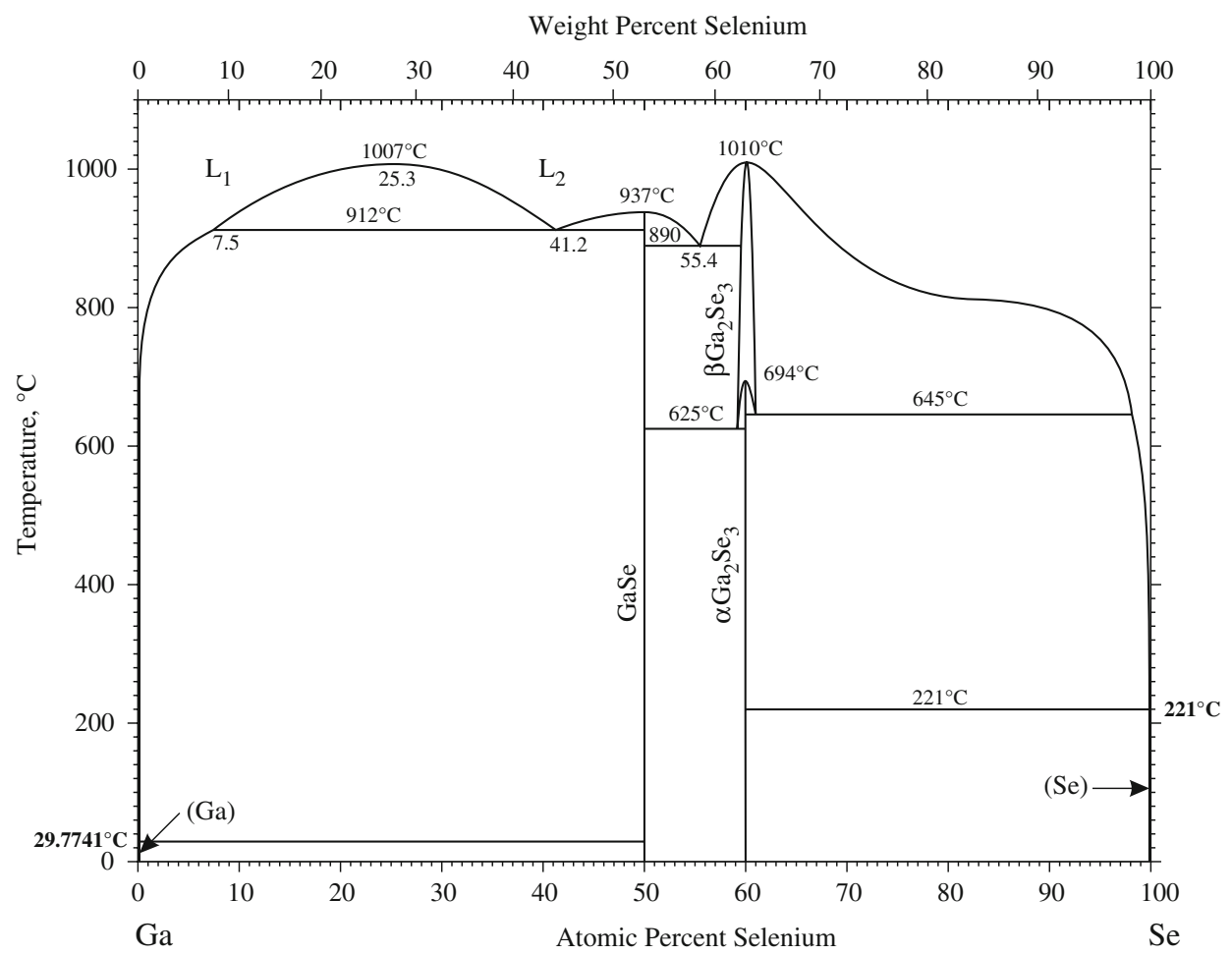

Fig. 1 Ga-Se phase diagram 